\section{Der Kardiotreff brummt}

Der Jahreskongress hat mit etwa 8200 Besuchern wieder einen neuen Rekord erreicht, das Mannheimer Tagungsgebäude ist dafür eigentlich schon fast zu klein. Aber diese drangvolle Enge ist gewollt, sie fördert die Kommunikation vor allem auch in den Ausstellungsebenen. Die Pharma- und Geräteindustrie nutzt den Jahreskongress längst als ideale Plattform für die Anpreisung ihrer Produkte, aber auch für Symposien: Über 50 waren es diesmal, eine ebenfalls rekordverdächtige Zahl. Die Kommerzialisierung des Kongresses macht große Fortschritte.

\section{"Fire and Ice" in der Rhythmologie}

Das thematische Angebot war attraktiv, dafür sorgte auch die Tagungspräsidentin Prof. Dr. Ellen Hoffmann vom Herzzentrum München-Bogenhausen, in deren Spezialgebiet, der Rhythmologie, die technische Entwicklung mit immer neuen Ansätzen überrascht. Ablation heißt das neue Zauberwort in der Therapie des Vorhofflimmerns. Ellen Hoffmanns Herz hängt an einer „eiskalten“ Technik, am Cryoballon. Hoffmann: „Dieses neue Verfahren wird derzeit in der kontrollierten Studie "Fire and Ice" unter der Leitung von Prof. Dr. Karl-Heinz Kuck und in der Registerstudie „FREEZE Cohort Study“ unter meiner Leitung mit dem Standardverfahren der Radiofrequenzablation verglichen und überprüft."

\section{Sorgen um den Nachwuchs}

Die demografische Entwicklung und auch der Erfolg der Akutkardiologe be- scheren immer mehr Herzkranke. Sie alle aber künftig kardiologisch zu versorgen dürfte schwierig werden, denn es fehlt an Nachwuchs. Diese Sorge treibt nicht nur den Gesellschaftspräsidenten Prof. Georg Ertl, Würzburg, sei Jahren um. Die DGK setzt sich nun verstärkt ein, junge Mediziner und Forscher für die Herzfächer zu begeistern, vor allem aber die Strukturen der Ausbildung zu überdenken. Denn, so Ertl: „Die jungen Menschen sind nicht mehr bereit, ihre Familien auf Spiel zu setzen, um ihre Karriere in der Medizin voran zu treiben. Das ist durchaus zu respektieren."

\section{Nachwuchsmangel vor allem in der Peripherie spürbar}

Ertl:„,Wir sehen mit einer gewissen Sorge, dass, besonders was hochqualifizierten und kompetitiven Nachwuchs angeht, nicht so viel nachkommt, wie wir uns das wünschen würden. Während der Engpass an den Universitätskliniken noch nicht spürbar ist, klagen Peripherie-Krankenhäuser mittlerweile über Mangel." Die DGK-Initiativen zur Problemlösung: Mit dem neu geschaffenen Otto-HessPromotionsstipendium werden Promovierende mit interessanten Dissertationsthemen gefördert: mit 500 Euro pro Monat über ein Jahr. Das soll ein Anreiz sein, weiter in der Forschung zu bleiben. Ähnliche Ziele verfolgt die DGK mit einem breiten Angebot an Preisen, Stipendien und Reisekostenzuschüssen. So bietet Die DGK-Arbeitsgruppe "German Chapter of Young Cardiologists“ jungen

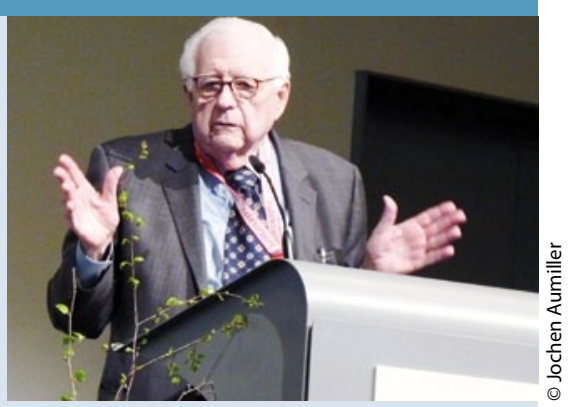

Eugene Braunwald gab sich die Ehre auf der gemeinsamen ACC-DGK-Sitzung in Mannheim.

Leuten die Möglichkeit, früh in die wissenschaftlichen Organisationen einzusteigen. Auch über Drittmittel finanzierte Stellen an den Kliniken sollen zur Entspannung der Lage beitragen, indem sie jungen Kardiologinnen und Kardiologen erlauben, sich eine Zeit lang ausschließlich der Forschung zu widmen.

\section{Eugene Braunwald - Nestor der US-Kardiologie}

Ein Highlight zumindest für die DGK war die gemeinsame Sitzung des ACC-DGKChapters. Dieses „Kapitel“ wächst aus gemeinsamen Gründungswurzeln, wie Festredner Berndt Lüderitz schilderte. Aber was ist ein Kapitel? Nach Lexikon "eine Körperschaft der zu einer Domkirche oder Stiftskirche gehörenden Geistlichen". Amerikanischer "Domherr" und Nestor der Kardiologie, Eugene Braunwald, folgte dem Ruf und weihte seine Zuhörer in die unvergleichliche TIMI-Studienreihe zur antithrombotischen Therapie ein. Eine kardiologische VIP-Sitzung der Sonderklasse.

Jochen Aumiller I 